Behavioral/Cognitive

\title{
Cholinergic Contributions to Supramodal Attentional Processes in Rats
}

\author{
Vladimir Ljubojevic, ${ }^{1,2}$ Paul Luu, ${ }^{2,3}$ and Eve De Rosa ${ }^{1,2}$ \\ ${ }^{1}$ Department of Psychology, University of Toronto, Toronto, Ontario M5S 3G3, Canada, ${ }^{2}$ Program in Neuroscience, University of Toronto, Toronto, Ontario \\ M5S 3E2, Canada, and '3Department of Physiology, University of Toronto, Toronto, Ontario M5S 1A8, Canada
}

Cholinergic neurotransmission has been shown to play an important role in modulating attentional processing of visual stimuli. However, it is not yet clear whether the neurochemical acetylcholine (ACh) is necessary exclusively for visual attention, or if it also contributes to attentional functions through some modality-independent (supramodal) mechanism. To answer this question, we examined the effects of reduced cortical cholinergic afferentation on both a traditional visual and a novel olfactory five-choice serial reaction time task (5-CSRTT), the benchmark rodent test of sustained attention in rats. Following the successful acquisition of both modalities of the task, the rats underwent either a cholinergic immunotoxic- or sham-lesion surgery of the nucleus basalis magnocellularis (NBM), the basal forebrain nuclei that provide the majority of neocortical ACh. Reduced cholinergic afferentation to the neocortex was induced by bilaterally infusing the cholinergic immunotoxin 192 IgG-saporin into the NBM. After surgery, ACh-NBM-lesioned rats performed comparably to sham-lesioned rats under the conditions of low attentional demand, but displayed behavioral decrements relative to the sham-lesioned rats when the attentional demands of the task were increased. Moreover, this decrement in attentional functioning correlated significantly with the number of choline acetyltransferase-immunoreactive cells in the NBM. Importantly, the nature of this behavioral decrement was identical in the visual and olfactory 5-CSRTTs. Together, these data suggest the presence of a supramodal attentional modulatory cortical network whose activity is dependent on cholinergic innervation from the NBM.

Key words: 192 IgG-saporin; acetylcholine; attention; olfactory; visual

\section{Introduction}

Converging evidence from human and animal studies indicates that acetylcholine $(\mathrm{ACh})$ plays an important role in modulating attentional processes (Stewart et al., 2001; Bentley et al., 2003; Botly and De Rosa, 2007, 2008; Furey et al., 2008). This modulatory influence is largely mediated by the ascending cholinergic fibers that originate in the posterior part of the basal forebrain (BF), called the nucleus basalis magnocellularis (NBM). The NBM provides the majority of cholinergic input to prefrontal and posterior parietal cortical regions (Mesulam et al., 1983) that are thought to be central nodes in the cortical attentional network (Posner and Petersen, 1990; Corbetta and Shulman, 2002). Current models propose that the frontoparietal cortical network facilitates sustained attention by modulating the input processing within sensory cortices, both through direct synapses and by mobilizing the ACh input from the BF into sensory cortices ( $\mathrm{Za}$ borszky, 2002; Disney and Aoki, 2008; Herrero et al., 2008),

Received March 7, 2013; revised Dec. 31, 2013; accepted Jan. 2, 2014.

Author contributions: V.L. and E.D.R. designed research; V.L. performed research; P.L. contributed unpublished reagents/analytic tools; V.L. and E.D.R. analyzed data; V.L. and E.D.R. wrote the paper.

This work was supported by Canadian Institute of Health Research Grant MOP102637 to E.D.R. and a National Science and Engineering Research Council Graduate Scholarship to V.L.

The authors declare no competing financial interests.

Correspondence should be addressed to Vladimir Ljubojevic or Eve De Rosa, Department of Psychology, University of Toronto, 100 St. George Street, Toronto, Ontario, Canada M5S 3G3. E-mail: vladimir.ljubojevic@mail.utoronto.ca or eve.derosa@cornell.edu.

DOI:10.1523/JNEUROSCI.1024-13.2014

Copyright $\odot 2014$ the authors $\quad 0270-6474 / 14 / 342264-12 \$ 15.00 / 0$ which results in more efficient detection and selection of behaviorally relevant stimuli (Sarter et al., 2001; Hasselmo and McGaughy, 2004). Consistent with this model, studies have found that disrupted cholinergic input to the neocortex can cause impairments in attentional function (Voytko et al., 1994; Bucci et al., 1998; Chiba et al., 1999; Burk et al., 2008; Botly and De Rosa, 2009, 2012) and that behavioral performance on attentional tasks is associated with increased ACh overflow within the frontal (Passetti et al., 2000; Arnold et al., 2002; Parikh et al., 2007) and parietal (Himmelheber et al., 2000, 2001) cortices.

The present study examines the consequences of cholinergic NBM lesions in rats performing not only the traditional visual five-choice serial reaction time task (5-CSRTT), a sustained attention task that requires the rat to continuously monitor multiple spatial locations for a briefly appearing target stimulus (Robbins, 2002), but also a novel olfactory version of the task. Previous studies found that performance on the visual 5-CSRTT induces a release of cortical ACh (Passetti et al., 2000; Dalley et al., 2001; McGaughy et al., 2002), and that the integrity of cortical cholinergic projections is necessary for optimal task performance (Muir et al., 1994; Risbrough et al., 2002; Lehmann et al., 2003; Dalley et al., 2004; Harati et al., 2008). Because previous studies have exclusively used visual targets in the 5-CSRTT, it is still unclear whether cholinergic neurotransmission in the frontoparietal cortical network contributes to attentional processing of stimuli in other modalities, i.e., in a supramodal manner. To 


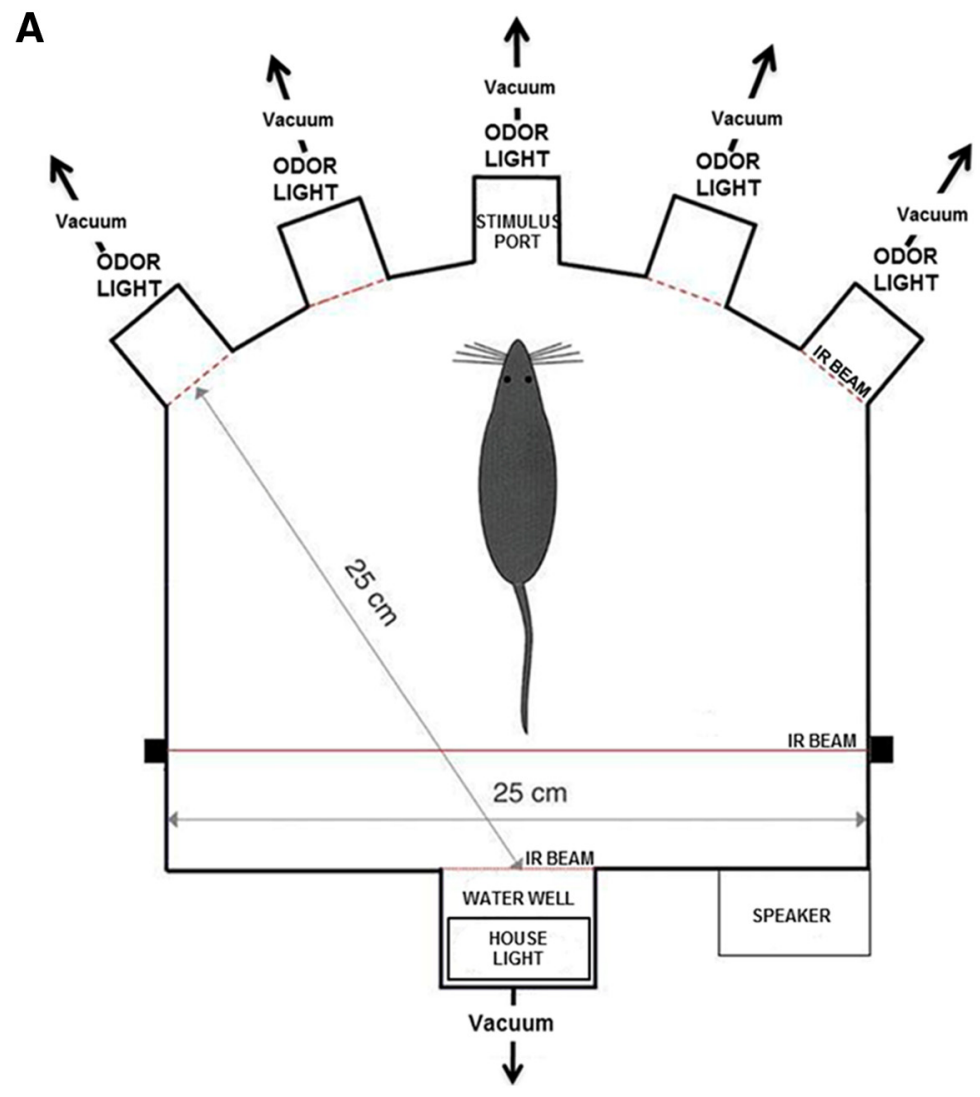

\section{B Single port olfactometer}

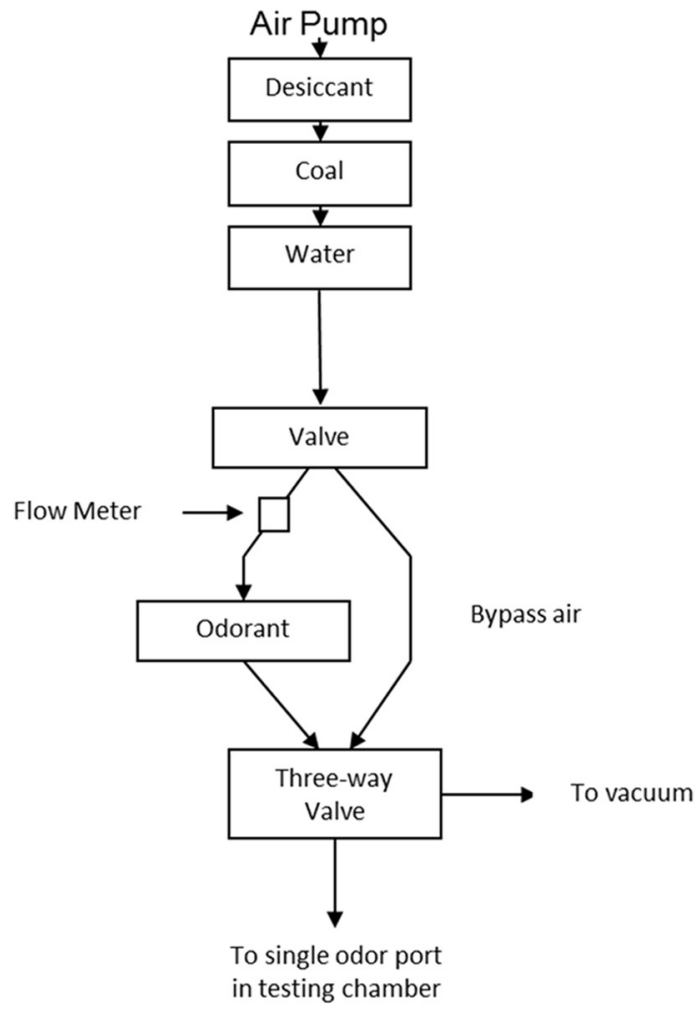

Figure 1. Apparatus. A, Illustration of the 5-CSRTT operant chamber (adapted from Bari et al., 2008) with five stimulus apertures where light and/or odor stimuli are presented. $\boldsymbol{B}$, Illustration of the part of the olfactometer that controls the supply of odor-enriched air into one stimulus port. Each stimulus port has an independent air supply.

address this question, we trained rats on both a visual (5C-v) and an olfactory (5C-o) version of the 5-CSRTT. We then injected the cholinergic-specific immunotoxin 192 IgG-saporin (Taniuchi and Johnson, 1985; Batchelor et al., 1989) into the NBM to reduce cholinergic afferentation to the neocortex. NBM lesions leave cholinergic afferentation to the olfactory cortex (OC) relatively intact. We hypothesized that if the cortical attentional system is supramodal, then we will observe postsurgical behavioral deficits on both the 5C-v and 5C-o. However, if the frontoparietal attentional system is exclusively responsible for visual attention, then rats' performance on the $5 \mathrm{C}$-o will be unaffected by the lesion.

\section{Materials and Methods}

Subjects. Subjects were 36 experimentally naive male Long-Evans rats (Charles River Laboratories) that weighed 225-250 g at the start of the experiment. Two of the rats failed to reach the behavioral performance criterion during presurgical training and were removed from the study. The rats were individually housed in $45-\mathrm{cm}$-long by 25 -cm-wide plastic tub cages and maintained on a reversed $12 \mathrm{~h}$ light/dark cycle (lights off at 8 A.M.), with behavioral testing occurring during the dark phase, typically between 9 A.M. and 4 P.M. Rats were maintained at $85 \%$ of ad libitum feeding weight during the experiment. The rats were initially water restricted for $24 \mathrm{~h}$. During their daily operant training/testing sessions, they received $0.05 \mathrm{ml}$ of water for every correct response and then had ad libitum access to water for 25-30 min after these sessions. This study was approved by the University of Toronto's Institutional Animal Care Committee.

Apparatus. The custom five-choice operant chamber $(25 \times 25 \times 25$ $\mathrm{cm}$; MED Associates), placed within a sound-isolating and ventilated wooden box, was used for all behavioral testing (Fig. $1 A$ ). Five stimulus apertures $(2.5 \times 2.5 \times 2.5 \mathrm{~cm})$, located at the front wall of the chamber, were arranged on the curved panel and raised $2.5 \mathrm{~cm}$ from the grid floor.
The stimulus apertures were equipped with a light-emitting diode, a nose port at the bottom through which an odor was released, an infrared (IR) beam that detected a nose poke, and a hole at the top through which an odor could be immediately vacuumed away from the port following the stimulus presentation. Another port was located at the back wall of the chamber, where a water reward was made available after a correct response. A house light and a vacuum port were mounted at the back wall of the chamber. Last, an IR beam was placed at the back of the chamber to detect and control the movement of the rats.

We used a custom olfactometer (Fig. 1B) to control the release of odor-enriched air into the operant chamber. The apparatus received the air supply from an air pump. The air was dried, filtered, rehydrated, and then directed into the vial with the odorant $(10 \%$ citral dissolved in scentless mineral oil; Sigma Aldrich). The odor-enriched air was then directed toward a three-way solenoid valve that either released the air into its stimulus port or toward the vacuum pump that removed the odor from the nose port. Each of the five stimulus ports had an independent air supply with air flow set at $1 \mathrm{~L} / \mathrm{min}$. The amount of odor-enriched air that was released into the stimulus port was controlled by the length of time its valve stayed open. This corresponded to the stimulus duration (StimD) parameter on the olfactory version of the task $(1,0.5$, or $0.25 \mathrm{~s})$.

Behavioral training. During the initial shaping, the rats were trained to do the following: (1) initiate the trial by breaking the IR beam at the back of the chamber for $2 \mathrm{~s},(2)$ respond to the target light by nose poking into the correct aperture (during the shaping, the light was presented indefinitely), and (3) collect the water reward by nose poking into the water port following the correct response. During the shaping, as well as throughout the rest of the experiment, each correct response was rewarded with $0.05 \mathrm{ml}$ of water.

Behavioral training on the 5-CSRTT started with the visual version of the task $(5 \mathrm{C}-\mathrm{v})$, so only light stimuli were presented. On each trial of the task, the rat had to respond to the brief light stimulus randomly presented in one of the five stimulus apertures. In addition to correct re- 
sponses, we recorded four types of errors: (1) incorrect responses, i.e., commission errors, when the rat nose poked in the wrong stimulus port; (2) omission errors when the rat failed to respond within allocated time period; (3) premature responses when the rat responded before the stimulus presentation; and (4) perseverative responses when the rat responded to multiple locations within the same trial. The first stage of the 5-CSRTT training had the following parameters: an StimD of $5 \mathrm{~s}$, an intertrial interval (ITI) of $3 \mathrm{~s}$, and a limited hold (LH) period of $5 \mathrm{~s}$. To proceed to the next stage of training, the rat had to achieve a behavioral criterion of having 18 of 20 correct trials at any point during the session as well as an accuracy of $\geq 80 \%$ and an omission rate of $\leq 20 \%$. The subsequent stages of behavioral training had progressively shorter StimDs and progressively longer ITIs, but the behavioral criterion stayed the same for each stage of training. Rats were considered to have completed the training for the visual version of the task when they met the behavioral criterion during the session with the following trial parameters: StimD, $1 \mathrm{~s}$; ITI, $5 \mathrm{~s}$; and LH, $5 \mathrm{~s}$ (baseline conditions).

Following successful acquisition of the $5 \mathrm{C}-\mathrm{v}$ task, the rats were trained on the olfactory version of the 5-CSRTT (5C-o). The first training stage involved coupled presentation of both visual and odor stimuli under baseline conditions and proceeded for $7 \mathrm{~d}$. After that, odor stimuli alone were presented, and the rats continued the training until they met the behavioral criterion on the olfactory task under the baseline conditions of a $1 \mathrm{~s} \mathrm{StimD,} 5 \mathrm{~s}$ ITI, and $5 \mathrm{~s} \mathrm{LH}$. The training stage with only odor stimuli presented was completed after five training sessions. All shaping sessions were limited to $20 \mathrm{~min}$ or 60 trials, and all testing sessions were 60 trials.

At the end of the training, 27 rats were assigned into either a shamlesion $(N=10)$ or ACh-NBM-lesion $(N=17)$ surgical group. The two groups were matched on presurgical performance using the percentage of correct responses on the final two sessions of $5 \mathrm{C}-\mathrm{v}$ training and the final two sessions of $5 \mathrm{C}$-o training as the measures of task performance. Following surgery, the sham-lesioned and ACh-NBMlesioned rats were subjected to postsurgical behavioral testing, which allowed us to examine the consequences of reduced cholinergic afferentation to the neocortex on 5C-v and 5C-o performance. An additional seven rats were subsequently trained under the same training protocol to be tested with olfactory control procedures (behavioral control group).

Olfactory control procedures. After the completion of behavioral training, a group of seven rats underwent a series of tests to ensure that the rats were using olfactory, somatosensory, or auditory stimuli to identify target apertures in the 5C-o task. The rats were tested in three conditions based on the type of stimuli that were displayed: (1) the olfactory condition (5C-o task), in which odor-enriched air was presented as the target stimulus; (2) the somatosensory condition, in which clean air was presented as the target stimulus; (3) the auditory condition, in which no air was released into the apertures, however the solenoid valve associated with the target aperture was still opened. The auditory condition was used to examine whether the rats were able to detect the target aperture based solely on the sound associated with the opening and closing of the solenoid valves. Each stimulus condition was tested in separate testing sessions, at three stimulus durations $(1,0.5$, and $0.25 \mathrm{~s}$; airflow of 1 $\mathrm{L} / \mathrm{min}$ ) in a counterbalanced order. Subsequently, the rats were tested in sessions that included all three trial types, i.e., 40 trials of olfactory conditions, 10 trials of somatosensory condition, and 10 trials of auditory condition, at each stimulus duration, i.e., 1, 0.5, and $0.25 \mathrm{~s}$ (airflow of 1 $\mathrm{L} / \mathrm{min}$ ). All of these testing sessions included 60 trials, with an ISI of $3 \mathrm{~s}$ and an LH of $5 \mathrm{~s}$.

Surgery. The remaining 27 rats were assigned into either the shamlesion $(N=10)$ or the ACh-NBM-lesion $(N=17)$ surgical group immediately following the behavioral training. All surgeries were performed under aseptic conditions using isoflurane as the anesthetic (3\% isoflurane with $1 \mathrm{~L} / \mathrm{min}$ oxygen for induction; $\sim 2 \%$ isoflurane with $1 \mathrm{~L} / \mathrm{min}$ oxygen for maintenance of anesthesia). Immediately before the surgery, the rats received a subcutaneous injection of the analgesic buprenorphine $(0.03 \mathrm{mg} / \mathrm{kg})$ and an intraperitoneal injection of atropine $(0.05$ $\mathrm{mg} / \mathrm{kg}$ ) to prevent fluid buildup in the lungs. The cholinergic immunotoxic lesions were accomplished by injecting $0.2 \mu \mathrm{l}$ of $0.2 \mu \mathrm{g} / \mu \mathrm{l} 192$
IgG-saporin (Advanced Targeting Systems; lot 64-124) dissolved in sterile $0.1 \mathrm{M}$ PBS, pH 7.4. The sham lesions involved the injection of $0.2 \mu \mathrm{l}$ of sterile $0.1 \mathrm{M}$ PBS, pH 7.4. The injection rate was $0.1 \mu \mathrm{l} / \mathrm{min}$ through a 26-gauge Hamilton syringe, with an additional 3 min delay before the retraction of the injection. The NBM lesion was performed bilaterally at two sites: $-0.72 \mathrm{~mm}$ anteroposterior (AP), $\pm 2.5 \mathrm{~mm}$ mediolateral (ML), and $-8.3 \mathrm{~mm}$ dorsoventral (DV); and $-1.32 \mathrm{~mm} \mathrm{AP}, \pm 3.0 \mathrm{~mm} \mathrm{ML}$, and $-7.3 \mathrm{~mm}$ DV (Paxinos and Watson, 2007). The choice of coordinates for lesioning and the dose of immunotoxin were based on pilot surgeries performed in our laboratory. The body temperature of each rat was maintained with a homeothermic blanket throughout the surgery. After the injections were complete, a small piece of sterile gelfoam was applied over the exposed skull to control any bleeding, and the wound was closed with $7 \mathrm{~mm}$ removable staples. Then, we applied topical analgesic ointment EMLA (2.5\% lidocaine and $2.5 \%$ prilocaine) around the staples. To prevent dehydration, the rats were given the injection of warm saline $(0.9 \% \mathrm{NaCl}, 1 \mathrm{ml} / 100 \mathrm{~g}$ body weight, s.c.) immediately after surgery.

Postsurgical testing procedures. The rats were given $14 \mathrm{~d}$ of postsurgical recovery with access to ad libitum water and food. They were water restricted $24 \mathrm{~h}$ before the start of postsurgical testing. During postsurgical testing, the experimenters were blind to the surgical group of each animal. Each session was 60 trials long. The testing involved four stages defined by the following different parametric manipulations: (1) testing at baseline conditions (StimD, $1 \mathrm{~s}$; ITI, $5 \mathrm{~s}$; LH, $5 \mathrm{~s}$ ) for four session on each version of the task (lights only followed by odor only); (2) testing with an StimD of $0.5 \mathrm{~s}$ (ITI, $5 \mathrm{~s} ; \mathrm{LH}, 5 \mathrm{~s}$ ) for seven sessions on each version of the task; (3) testing with an StimD of $0.25 \mathrm{~s}$ (ITI, $5 \mathrm{~s}$; LH, $5 \mathrm{~s}$ ) for seven sessions on each version of the task; (4) testing with within session variable ITIs (StimD, $1 \mathrm{~s}$; LH, $5 \mathrm{~s}$ ) for four sessions on each version of the task. Trials with ITI values of $2,4,6$, and $8 \mathrm{~s}$ were pseudorandomly distributed within each 60 trial session for all versions of the task.

Histological analyses. Following the completion of the postsurgical testing, the rats were anesthetized with sodium pentobarbital $(60 \mathrm{mg} / \mathrm{kg}$, i.p.) and then perfused with $\sim 150 \mathrm{ml}$ of ice-cold normal saline followed by $\sim 150 \mathrm{ml}$ of ice-cold $4 \%$ paraformaldehyde. After the brain extraction, the brains were postfixed in $4 \%$ paraformaldehyde for $2 \mathrm{~h}$ at $4{ }^{\circ} \mathrm{C}$ and then transferred to a solution of $20 \%$ sucrose in $\mathrm{PBS}(0.1 \mathrm{M}, \mathrm{pH} 7.4)$ where they were kept for 1 week at $4^{\circ} \mathrm{C}$.

The brains were sliced to sections $60 \mu \mathrm{m}$ thick using a cryostat equipped with a freezing-sliding microtome (Leica Microsystems), and the adjacent slices were used in either acetylcholinesterase (AChE) histochemistry, choline acetyltransferase (ChAT) immunohistochemistry, or parvalbumin immunohistochemistry assays. AChE histochemistry was executed according to the method described by Paxinos and Watson (2007) to determine the extent of cholinergic input to the rat cortex. ChAT and parvalbumin immunohistochemistry were executed according to methods described previously (De Rosa et al., 2001) to determine the potential cholinergic and GABAergic cell body loss within the basal forebrain regions.

Histological quantification. All photomicrographs of the target areas were taken using a using a Leica light microscope (DM4000B) and Openlab image analysis software (Quorum Technologies). Photomicrographs were taken with $5 \times$ magnification. During the histological quantification, the experimenter was blind to each rat's surgical condition. Choline acetyltransferase- and parvalbumin-immunoreactive cells in the basal forebrain nuclei were counted using a more biased regions of interest (ROIs) approach, rather than using unbiased stereology (McGaughy et al., 2002; Marques Pereira et al., 2005; Harati et al., 2008, 2011; Tait and Brown, 2008; Greferath et al., 2012). These ROIs were defined based on the Paxinos and Watson (2007) rat neuroanatomy atlas, and comparable sections from each rat were treated identically.

Choline acetyltransferase- and parvalbumin-immunoreactive cells were counted bilaterally on three brain sections containing the nucleus basalis magnocellularis at approximately the following coordinates relative to bregma (Paxinos and Watson, 2007): (1) At $-0.96 \mathrm{~mm} \mathrm{AP}$, the photomicrograph was taken by positioning the bottom left (in the right hemisphere) or the bottom right (in the left hemisphere) corner of the Openlab image window at the utmost dorsomedial point of the posterior part of the anterior commissure (ACP) so that the ACP was not visible. 

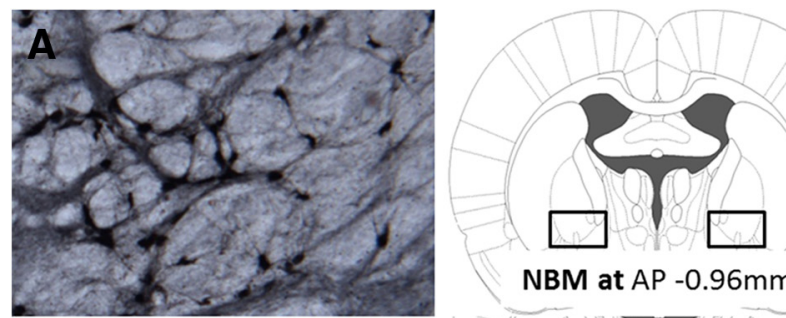

NBM at $A P-0.96 m m$
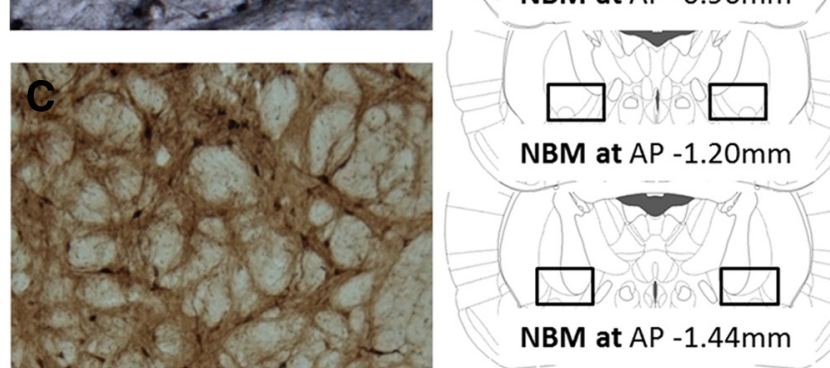
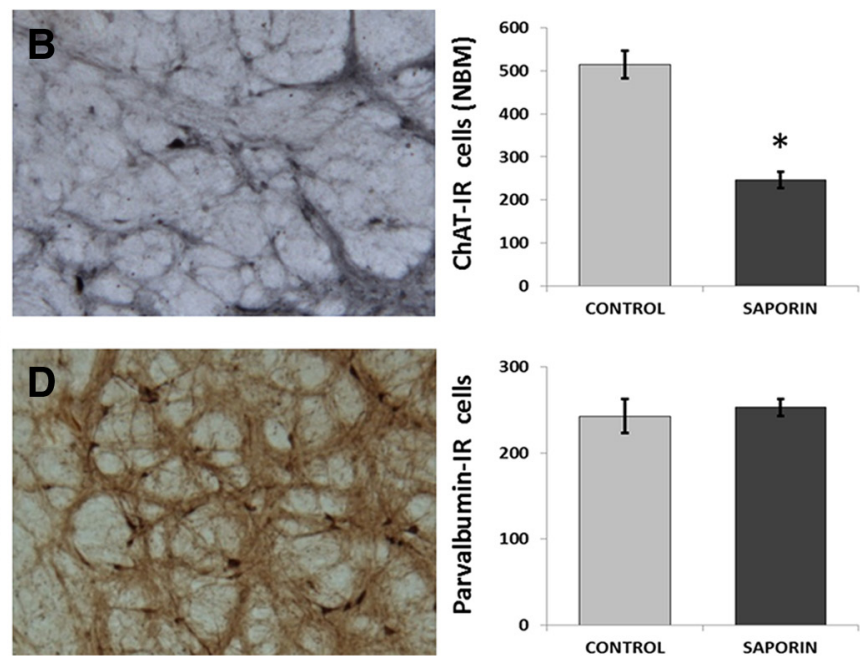

Figure 2. ChAT and parvalbumin immunohistochemistry of the nucleus basalis magnocellularis. $\boldsymbol{A}-\boldsymbol{D}$, The figure shows the photomicrographs of the ChAT- and parvalbumin-immunoreactive cells in the NBMs of ACh-NBM-lesioned $(B, D)$ and sham-lesioned $(A, C$ rats. There was a marked decrease in the number of ChAT-immunoreactive cells in the NBMs of the ACh-NBM-lesioned rats $(\boldsymbol{B})$ when compared to controls $(\boldsymbol{A})$. The number of parvalbumin-immunoreactive cells in the NBM was comparable between the groups $(\boldsymbol{C}, \boldsymbol{D})$. The rectangular outlines superimposed on the rat brain coronal schematics approximately correspond to the NBM cell-counting frames. Rat brain schematics were adapted from Paxinos and Watson (2007), and displayed coordinates refer to the AP plane $\left(N_{\text {sham lesioned }}=10 ; N_{\text {ACh-NBM lesioned }}=15\right) .{ }^{*} p<0.001$. Error bars indicate SEM.

Table 1. Number (mean \pm SEM) of ChAT- and parvalbumin-immunoreactive cells in the basal forebrain subregions

\begin{tabular}{lllr}
\hline Brain area & Control & Saporin & \% difference \\
\hline ChAT & & & \\
NBM & $514.30 \pm 95.40$ & $246.20 \pm 70.36^{*}$ & -52.1 \\
MS/NDB & $420.80 \pm 41.10$ & $431.93 \pm 31.32$ & 2.6 \\
HDB & $103.80 \pm 24.85$ & $107.67 \pm 15.97$ & 3.7 \\
Parvalbumin & & & \\
NBM & $242.90 \pm 62.35$ & $252.93 \pm 37.25$ & 4.1 \\
\hline
\end{tabular}

Summary of the findings following the ChAT and parvalbumin immunostaining shows that there was a significant loss of cells in the NBM of ACh-NBM-lesioned rats compared to controls. There were no group differences in the number of ChAT-immunoreactive cells in the MS/VDB and in the HDB, and no differences in the number of parvalbumin-immunoreactive cells in the NBM.

${ }^{*} p<0.001$.

The counting frame was $1.5 \mathrm{~mm}$ wide and $1.2 \mathrm{~mm}$ high. All cells in the photomicrograph were counted. The majority of the cells were positioned along the ventrolateral border of the internal capsule (IC). (2) At $-1.20 \mathrm{~mm}$ AP, we used the ventral border of the fornix as the bottom border of the Openlab image window. The window was then moved toward lateral parts of the brain until the medialmost border of the IC became aligned with the side border of the Openlab image window. After the photomicrograph was taken, we used the Openlab ruler to exclude the regions that were within 400 measurement units along either the left (for the right hemisphere) or right (for the left hemisphere) border of the photomicrograph and 300 measurement units along the bottom border of the photomicrograph. The remaining part of the photomicrograph was used as the counting frame at this AP coordinate. The counting frame was $1.2 \mathrm{~mm}$ wide and $0.96 \mathrm{~mm}$ high. (3) At $-1.44 \mathrm{AP}$, we used the dorsal border of the fornix as a bottom border of the Openlab image window. The window was then moved toward lateral parts of the brain until the medialmost border of the IC aligned with the side border of the Openlab image window. From the photomicrograph taken in such a manner, we excluded the regions that were within 400 measurement units along the left (for the right hemisphere) or right (for the left hemisphere) border of the photomicrograph. The counting frame was $1.2 \mathrm{~mm}$ wide and $1.2 \mathrm{~mm}$ high. We also excluded the cells that were visible along dorsomedial border of the IC.

Cell counts from the medial septum (MS)/vertical limb nucleus of the diagonal band of Broca (VDB) were taken from three sections at approximately the following coordinates: $+1.20 \mathrm{~mm} \mathrm{AP},+0.96 \mathrm{~mm} \mathrm{AP}$, and $+0.72 \mathrm{~mm}$ AP relative to bregma (Paxinos and Watson, 2007). At all three coordinates, we took the photomicrograph by positioning the middle point of the bottom border of the Openlab image window over the ventralmost point at which the two hemispheres were still connected. Furthermore, we counted the cells that were within 450 measurement units on both the left and right sides of the photomicrograph axis. The counting frame was $0.7 \mathrm{~mm}$ wide and $1.2 \mathrm{~mm}$ high.

Cell counts from the horizontal limb nucleus of the diagonal band of Broca (HDB) were taken bilaterally from a section at approximately $+0.48 \mathrm{~mm}$ AP relative to bregma (Paxinos and Watson, 2007). We took the photomicrograph by positioning the top right corner (right hemisphere) or top left corner (left hemisphere) of the Openlab image window on the ventralmost point at which the two hemispheres were still connected. We then excluded the area that fell within 600 measurement units of the bottom border of the photomicrograph and the area that was within 900 measurement units from the left (right hemisphere) or right (left hemisphere) border of the photomicrograph. The counting frame was $1 \mathrm{~mm}$ wide and $0.8 \mathrm{~mm}$ high.

Within each counting frame in the NBM, MS/VDB, and HDB, we counted only cells that were clearly distinguishable from the background with well-defined borders of the cell body. The cells with lighter staining and/or blurred borders were ignored.

AChE densitometry was conducted using the software package Scion. With this software we obtained the optical density (OD) values from several brain regions: the prefrontal cortex (at $+2.76 \mathrm{~mm} \mathrm{AP}$ and +1.32 $\mathrm{mm}$ AP relative to bregma), the olfactory cortex (at $+0.60 \mathrm{~mm} \mathrm{AP})$, the hippocampus (at $-3.24 \mathrm{~mm} \mathrm{AP}$ ), the posterior parietal cortex (at -3.96 $\mathrm{mm} \mathrm{AP})$, and the primary and secondary visual cortices $(-4.80$ to -5.16 mm AP; Paxinos and Watson, 2007). These raw OD values were further divided by the optical density value measured from the striatum of each rat. Ratios obtained in such a manner were used in the statistical analysis instead of the raw OD values to adjust for potential differences in staining intensity across different rats.

\section{Results}

\section{Olfactory control procedures}

At the end of the training, the rats that were subjected to testing with the olfactory control procedures (behavioral control group) achieved a level of performance that was identical to that of the rats who took part in the lesion study (sham-lesioned and AChNBM-lesioned groups). A mixed-design ANOVA with group (behavioral control, sham lesioned, and ACh-NBM lesioned) as the between-subject factor and session (final two training ses- 

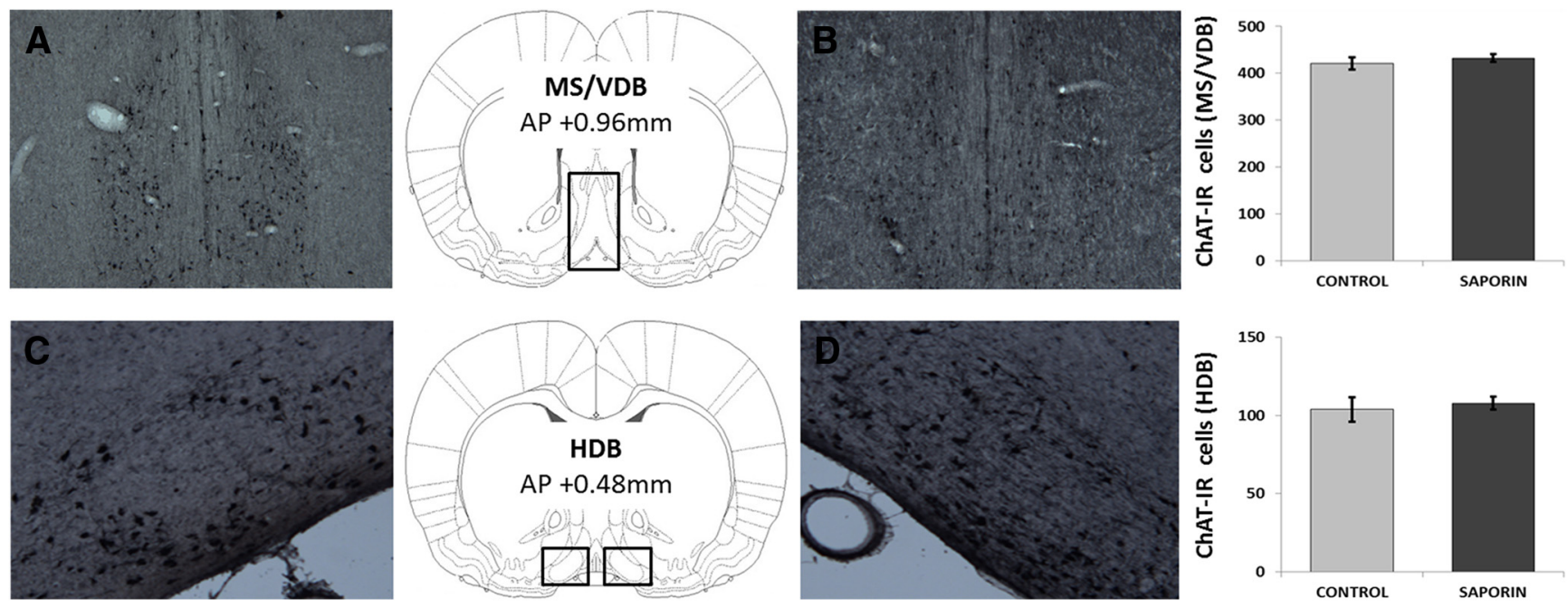

Figure 3. ChAT immunohistochemistry of the MS/VDB and the HDB. $A-D$, The figure depicts the rat MS/VDB $(\boldsymbol{A}, \boldsymbol{B})$ and $\mathrm{HDB}(\boldsymbol{C}, \boldsymbol{D})$ following the ChAT immunostaining. There was no group

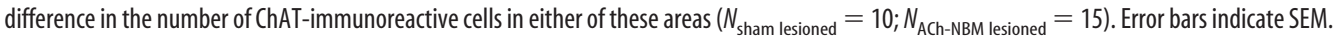

Table 2. Adjusted OD values (mean \pm SEM) from various cortical regions following AChE histochemistry

\begin{tabular}{|c|c|c|c|c|c|}
\hline Brain area (distance anterior to bregma in $\mathrm{mm}$ ) & Control & Saporin & $\%$ difference & $t_{(\mathrm{df}=23)}$ & $p$ \\
\hline Prelimbic $(+2.76)$ & $0.51 \pm 0.02$ & $0.42 \pm 0.02$ & -17.6 & 3.59 & 0.002 \\
\hline Frontal area $3(+2.76)$ & $0.57 \pm 0.02$ & $0.46 \pm 0.01$ & -19.3 & 4.76 & $<0.001$ \\
\hline Sensorimotor $(+1.32)$ & $0.56 \pm 0.01$ & $0.43 \pm 0.02$ & -23.2 & 5.26 & $<0.001$ \\
\hline Olfactory $(+0.60)$ & $0.44 \pm 0.02$ & $0.43 \pm 0.02$ & -2.2 & 0.35 & n.s. \\
\hline Hippocampus $(-3.24)$ & $0.65 \pm 0.01$ & $0.63 \pm 0.01$ & -3.1 & 1.16 & n.s. \\
\hline Posterior parietal $(-3.96)$ & $0.54 \pm 0.01$ & $0.46 \pm 0.01$ & -14.8 & 5.90 & $<0.001$ \\
\hline Visual $(-4.80$ to -5.16$)$ & $0.46 \pm 0.02$ & $0.40 \pm 0.02$ & -13.0 & 2.41 & 0.024 \\
\hline
\end{tabular}

The table shows the effect of $192 \mathrm{lgG}$-saporin lesion on the adjusted $0 \mathrm{D}$ values measured from various cortical regions following AChE staining, together with the results of statistical analysis. Anterior-posterior distance from bregma at which OD value was measured is shown in the brackets.

sions) as the repeated measures factor was used to assess the rats' performance, as measured by the percentage of correct responses per session on the two versions of the task. The analysis revealed that there was no group difference in the percentage of correct responses in the final two sessions of training on either the $5 \mathrm{C}-\mathrm{v}\left(F_{(2,31)}<1\right.$, n.s. $)$ or 5C-o $\left(F_{(2,31)}<1\right.$, n.s. $)$. Testing with the olfactory control procedures revealed that the rats were using olfactory information to detect the target aperture.

We used a $2 \times 3 \times 3$ repeated measures ANOVA with session type (stimulus condition in separate sessions and stimulus conditions within a session), stimulus duration ( $1,0.5$, and $0.25 \mathrm{~s}$ ), and stimulus condition (olfactory, somatosensory, and auditory) as within-subject factors to analyze rats' performance on the fivechoice task. We observed a significant effect of stimulus condition on the percentage of correct responses per session $\left(F_{(2,12)}=\right.$ $565.38, p<0.001)$, with rats making more correct responses in the olfactory condition than in the somatosensory $\left(F_{(1,6)}=\right.$ 1044.67, $p<0.001)$ and auditory $\left(F_{(1,6)}=1087.50, p<0.001\right)$ conditions; the somatosensory and auditory conditions did not differ $\left(F_{(1,6)}<1\right.$, n.s.). Across the 12 sessions of the olfactory control procedure testing, the average percentage of correct responses per session in the olfactory condition was $80.22 \pm 1.16 \%$. On the other hand, the average percentages of correct responses in the somatosensory and auditory conditions were $20.67 \pm$ $1.21 \%$ and $18.77 \pm 1.53 \%$, respectively. In fact, a one-sample $t$ test revealed that the average percentages of correct responses in the somatosensory $\left(t_{(6)}=0.55, p=0.60\right.$, n.s.) and auditory conditions $\left(t_{(6)}=0.80, p=0.45\right.$, n.s. $)$ did not significantly differ from chance ( $20 \%$ of correct responses).
The principal analysis also revealed that the stimulus condition factor significantly affected the percentage of incorrect responses $\left(F_{(2,12)}=144.21, p<0.001\right)$, the percentage of omissions per session $\left(F_{(2,12)}=70.60, p<0.001\right)$, and the correct response latency $\left(F_{(2,12)}=7.42, p=0.008\right)$. Specifically, the rats made more incorrect responses, made more omissions, and had slower response latencies in the somatosensory (incorrect, $F_{(1,6)}=$ 125.00, $p<0.001$; omission, $F_{(1,6)}=77.68, p<0.001$; correct response latency, $F_{(1,6)}=39.97, p<0.001$ ) and auditory (incorrect, $F_{(1,6)}=512.13, p<0.001$; omission, $F_{(1,6)}=99.70, p<$ 0.001 ; correct response latency, $\left.F_{(1,6)}=10.57, p=0.017\right)$ conditions when compared to the olfactory condition. The somatosensory and auditory conditions did not differ on any of the measures. The numbers of premature $\left(F_{(2,12)}=2.17\right.$, n.s. $)$ or perseverative $\left(F_{(2,12)}<1\right.$, n.s. $)$ responses and the reward latency $\left(F_{(2,12)}<1\right.$, n.s.) were not affected by the stimulus condition factor.

\section{Immunohistological quantification}

Immunohistological analyses were performed on the brains of the rats that underwent the cholinergic-lesion or sham-lesion surgery. Immunohistological quantification revealed that two ACh-NBM-lesioned rats did not have a sufficient decrease in the number of cholinergic cells in the NBM. Specifically, the reduction in the number of ChAT-immunoreactive cells in the NBM of these rats did not meet the criterion of more than two SDs below the mean of the sham-lesioned group. These rats were removed from the behavioral analysis, leaving 15 rats in 

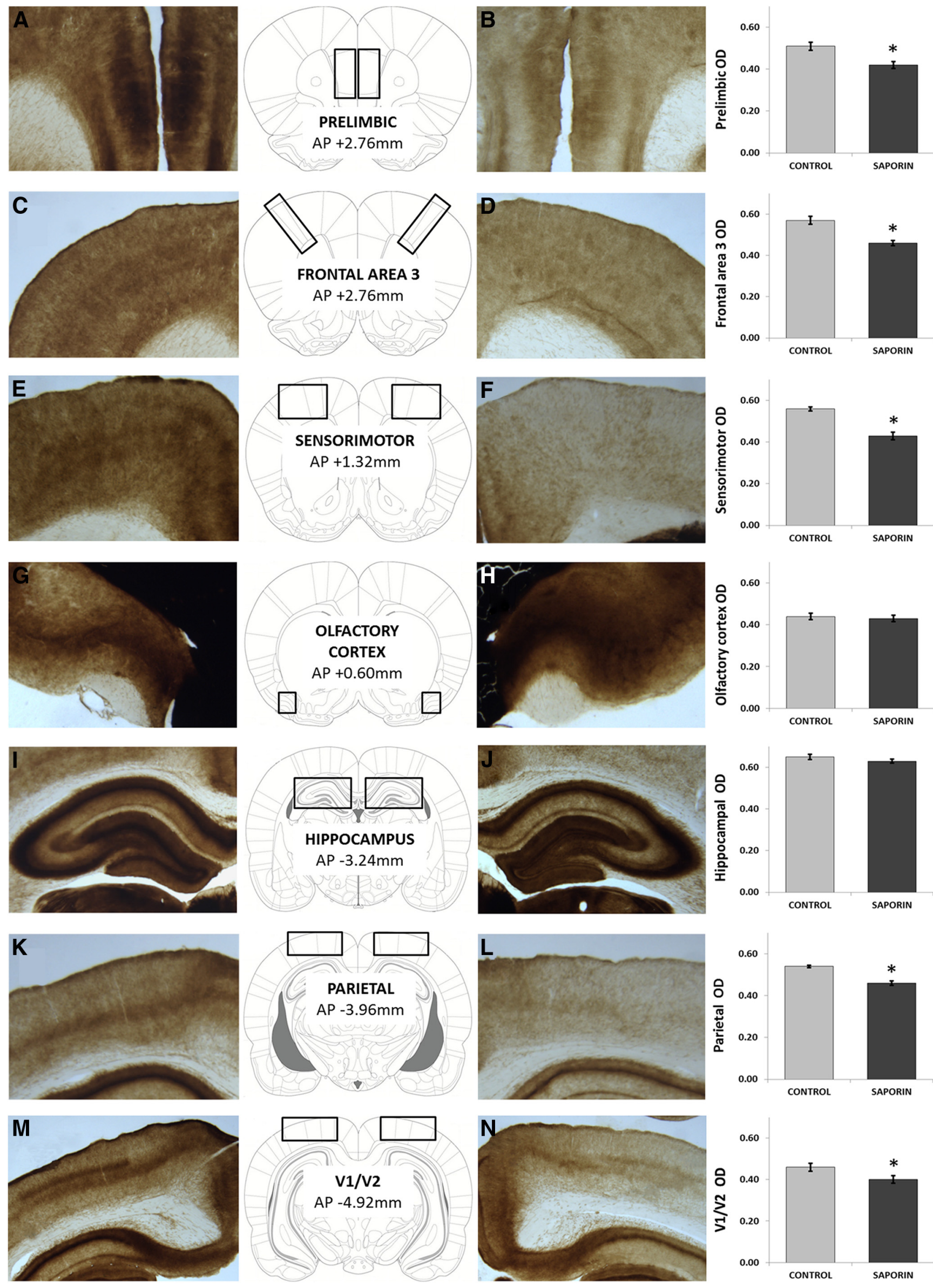
Table 3. Behavioral measures (mean + SEM) of the visual 5-CSRTT across different testing conditions

\begin{tabular}{|c|c|c|c|c|}
\hline Behavioral measure & StimD 1s & StimD 0.5 s & StimD $0.25 \mathrm{~s}$ & Variable ITI \\
\hline \multicolumn{5}{|l|}{ Correct response (\%) } \\
\hline Control & $71.17 \pm 3.23$ & $53.10 \pm 2.56$ & $38.12 \pm 2.68$ & $66.75 \pm 4.52$ \\
\hline Saporin & $64.92 \pm 2.64$ & $42.97 \pm 1.85^{* *}$ & $24.75 \pm 2.19^{* *}$ & $60.44 \pm 3.35$ \\
\hline \multicolumn{5}{|l|}{ Omissions (\%) } \\
\hline Control & $15.83 \pm 2.21$ & $21.88 \pm 2.91$ & $26.93 \pm 3.82$ & $13.42 \pm 3.45$ \\
\hline Saporin & $19.22 \pm 1.80$ & $28.86 \pm 2.37$ & $40.80 \pm 3.12^{*}$ & $16.67 \pm 2.62$ \\
\hline \multicolumn{5}{|l|}{ Incorrect response (\%) } \\
\hline Control & $6.50 \pm 1.44$ & $17.81 \pm 1.73$ & $25.60 \pm 1.73$ & $9.83 \pm 2.24$ \\
\hline Saporin & $8.33 \pm 1.18$ & $19.43 \pm 1.41$ & $24.33 \pm 1.41$ & $11.06 \pm 1.78$ \\
\hline \multicolumn{5}{|c|}{ Premature response (\%) } \\
\hline Control & $6.37 \pm 1.40$ & $7.10 \pm 0.99$ & $9.00 \pm 1.38$ & $9.00 \pm 2.00$ \\
\hline Saporin & $7.47 \pm 1.14$ & $8.75 \pm 0.81$ & $9.97 \pm 1.12$ & $10.89 \pm 1.51$ \\
\hline \multicolumn{5}{|l|}{ Water latency (s) } \\
\hline Control & $1.55 \pm 0.09$ & $1.75 \pm 0.10$ & $1.89 \pm 0.11$ & $1.69 \pm 0.04$ \\
\hline Saporin & $1.50 \pm 0.07$ & $1.65 \pm 0.08$ & $1.77 \pm 0.09$ & $1.74 \pm 0.09$ \\
\hline \multicolumn{5}{|l|}{ Correct latency (s) } \\
\hline Control & $1.08 \pm 0.09$ & $0.94 \pm 0.05$ & $1.42 \pm 0.34$ & $1.04 \pm 0.82$ \\
\hline Saporin & $1.25 \pm 0.08$ & $1.01 \pm 0.04$ & $2.18 \pm 0.28$ & $1.13 \pm 0.04$ \\
\hline \multicolumn{5}{|l|}{ Accuracy (\%) } \\
\hline Control & $91.63 \pm 2.21$ & $74.88 \pm 2.38$ & $59.82 \pm 2.75$ & $87.16 \pm 1.87$ \\
\hline Saporin & $88.63 \pm 1.84$ & $68.86 \pm 1.87$ & $50.43 \pm 2.33^{*}$ & $84.53 \pm 2.18$ \\
\hline
\end{tabular}

The table shows a summary of the rats' performance on the visual version of the 5 -CSRTT across different testing conditions. Note the significant group differences in the percentage of correct responses and percentage of omissions per session under the conditions of increased attentional demand (StimDs 0.5 and $0.25 \mathrm{~s}$ ).

${ }^{*} p<0.05 ;{ }^{* *} p<0.005$.

the ACh-NBM-lesioned group and 10 rats in the shamlesioned group.

\section{Cell counting}

Photomicrographs of sections of the NBM are shown in Figure 2. Two-tailed independent samples $t$ tests were used to compare the numbers of counted cells between sham-lesioned and AChNBM-lesioned rats. We observed a significant decrease in the number of ChAT-immunoreactive cells in the NBMs of AChNBM-lesioned rats when compared to the controls $\left(t_{(23)}=7.87\right.$, $p<0.001$; Table 1). The extent of the cholinergic cell loss in the NBM was, on average, $52.13 \%$ (SD, 13.68\%). On the other hand, the number of parvalbumin-immunoreactive cells in the NBM was equivalent between the two groups $\left(t_{(23)}=0.51\right.$, n.s. $)$. In addition, we did not observe any difference between the groups in the number of ChAT-immunoreactive cells in the MS/VDB $\left(t_{(23)}\right.$ $=0.77$, n.s. $)$ or the HDB regions $\left(t_{(23)}=0.48\right.$, n.s.; Table 1$)$. Sample photomicrographs of the MS/VDB and the HDB are shown in Figure 3. Finally, we observed no signs of nonspecific tissue damage within the brain regions that were investigated.

\section{AChE densitometry}

Two-tailed independent sample $t$ tests were used to compare the sham-lesioned and ACh-NBM-lesioned rats on the adjusted OD values (adjOD; raw OD value divided by striatal OD value) obtained from the AChE-stained slices. The analysis revealed that there was a significant decrease in the cholinergic input to frontoparietal and striate cortical regions in the ACh-NBM-lesioned rats compared to the sham-lesioned group. Moreover, there was

$\leftarrow$

Figure 4. AChE histochemistry. $A-N$, The figure depicts various cortical areas following the AChE staining: prelimbic cortex $(\boldsymbol{A}, \boldsymbol{B})$, frontal area $3(\boldsymbol{C}, \boldsymbol{D}))$, sensorimotor cortex $(\boldsymbol{E}, \boldsymbol{F})$, olfactory cortex $(\boldsymbol{G}, \boldsymbol{H})$, hippocampus $(\boldsymbol{I}, \boldsymbol{J})$, posterior parietal cortex $(\boldsymbol{K}, \boldsymbol{L})$, primary and secondary visual cortices $(\boldsymbol{M}, \boldsymbol{N})$ [as delineated by Paxinos and Watson (2007)]. We have observed significantly lower adjusted $O D$ values in all neocortical areas of ACh-NBM-lesioned rats $(B, D, F, L, N)$. On the other hand, the $O D$ values from olfactory cortex and hippocampus were equivalent for the two $\operatorname{groups}\left(N_{\text {sham lesioned }}=10 ; N_{\text {ACh-NBM lesioned }}=15\right) .{ }^{*} p<0.05$. Error bars indicate SEM. no group difference in the adjusted OD values from the hippocampus and olfactory cortex. Table 2 provides mean adjOD values $( \pm$ SEM) together with the results of the statistical analyses. Throughout the neocortical areas that were assessed, the loss of AChE-positive reaction products ranged from 13.0 to $23.2 \%$. Raw OD values from the striatum that were used for normalization did not differ between groups $\left(t_{(23)}<1\right.$; sham lesioned: mean, 248.4; SEM, 1.18; ACh-NBM lesioned: mean, 248.1; SEM, $0.73)$. Sample photomicrographs of the coronal sections from the regions of interest with AChE staining are shown in Figure 4.

\section{Postsurgical testing}

Postsurgical testing revealed group differences in the percentage of correct responses and the percentage of omissions per session under conditions of increased attentional demand in the task (see Effect of the 192 IgG-saporin lesion of the NBM, below). However, the percentage of incorrect and premature responses per session, as well as the correct response and reward latencies, remained unchanged following the 192 IgG-saporin lesion of the NBM in all testing conditions and on both versions of the task (Tables 3, 4). All comparisons were made using a mixed-design ANOVA with an $\alpha$ level of 0.05 . Finally, rats in both surgical groups made very few perseverative responses per session $(<1 \%)$, and therefore these data are not reported.

\section{Effect of manipulating the stimulus duration}

Postsurgical performance, in terms of the percentage of correct responses on two versions of the task, was examined using a mixed-design ANOVA with surgical group (ACh-NBM lesion and sham lesioned) as a between-groups factor and session (Days 1 to 4$)$ and stimulus duration (1, 0.5, and $0.25 \mathrm{~s})$ as within-subject factors. On the $5 \mathrm{C}-\mathrm{v}$ task, we observed a significant effect of stimulus duration $\left(F_{(2,46)}=137.44, p<0.001\right)$, a significant group effect $\left(F_{(1,23)}=14.27, p=0.001\right)$, and no interaction between the two $\left(F_{(2,46)}=1.56\right.$, n.s. $)$. Linear trend analysis revealed that both groups of rats made fewer correct responses in sessions with shorter stimulus duration (sham-lesioned rats, $F_{(1,9)}=44.16, p<$ 
Table 4. Behavioral measures (mean + SEM) of the olfactory 5-CSRTT across different testing conditions

\begin{tabular}{|c|c|c|c|c|}
\hline Behavioral measure & StimD 1s & StimD $0.5 \mathrm{~s}$ & StimD $0.25 \mathrm{~s}$ & Variable ITI \\
\hline \multicolumn{5}{|l|}{ Correct responses (\%) } \\
\hline Control & $82.96 \pm 2.40$ & $84.65 \pm 2.27$ & $82.64 \pm 2.12$ & $87.58 \pm 2.02$ \\
\hline Saporin & $84.03 \pm 1.96$ & $78.46 \pm 1.85^{*}$ & $69.23 \pm 1.73^{* * *}$ & $85.67 \pm 2.24$ \\
\hline \multicolumn{5}{|l|}{ Omissions (\%) } \\
\hline Control & $9.63 \pm 1.64$ & $8.91 \pm 1.82$ & $7.86 \pm 1.49$ & $4.75 \pm 0.52$ \\
\hline Saporin & $8.66 \pm 1.34$ & $14.70 \pm 1.49^{*}$ & $17.02 \pm 1.21^{* * *}$ & $5.61 \pm 1.79$ \\
\hline \multicolumn{5}{|c|}{ Incorrect responses (\%) } \\
\hline Control & $3.38 \pm 0.65$ & $3.14 \pm 0.47$ & $3.98 \pm 0.61$ & $3.06 \pm 0.52$ \\
\hline Saporin & $2.89 \pm 0.53$ & $3.00 \pm 0.38$ & $4.95 \pm 0.50$ & $2.61 \pm 0.59$ \\
\hline \multicolumn{5}{|c|}{ Premature responses (\%) } \\
\hline Control & $3.88 \pm 1.46$ & $2.98 \pm 0.95$ & $5.48 \pm 1.31$ & $4.33 \pm 1.81$ \\
\hline Saporin & $4.28 \pm 1.19$ & $3.70 \pm 0.77$ & $8.71 \pm 1.07$ & $6.06 \pm 1.56$ \\
\hline \multicolumn{5}{|l|}{ Water latency (s) } \\
\hline Control & $2.04 \pm 0.13$ & $1.96 \pm 0.14$ & $1.95 \pm 0.15$ & $1.88 \pm 0.04$ \\
\hline Saporin & $1.95 \pm 0.11$ & $1.90 \pm 0.11$ & $1.86 \pm 0.12$ & $1.83 \pm 0.04$ \\
\hline \multicolumn{5}{|l|}{ Correct latency (s) } \\
\hline Control & $1.40 \pm 0.11$ & $1.31 \pm 0.09$ & $1.47 \pm 0.07$ & $1.40 \pm 0.81$ \\
\hline Saporin & $1.44 \pm 0.09$ & $1.36 \pm 0.07$ & $1.59 \pm 0.06$ & $1.36 \pm 0.04$ \\
\hline \multicolumn{5}{|l|}{ Accuracy (\%) } \\
\hline Control & $96.09 \pm 0.82$ & $96.42 \pm 0.54$ & $95.41 \pm 0.79$ & $96.62 \pm 0.85$ \\
\hline Saporin & $96.68 \pm 0.75$ & $96.32 \pm 0.59$ & $93.33 \pm 0.75$ & $97.04 \pm 0.76$ \\
\hline
\end{tabular}

The table shows a summary of the rats' performance on olfactory version of the 5 -CSRTT across different testing conditions. Note the significant group differences in the percentage of correct responses and percentage of omissions per session under the conditions of increased attentional demand (StimDs 0.5 and $0.25 \mathrm{~s}$ ).

${ }^{*} p<0.05 ;{ }^{* * *} p<0.001$.
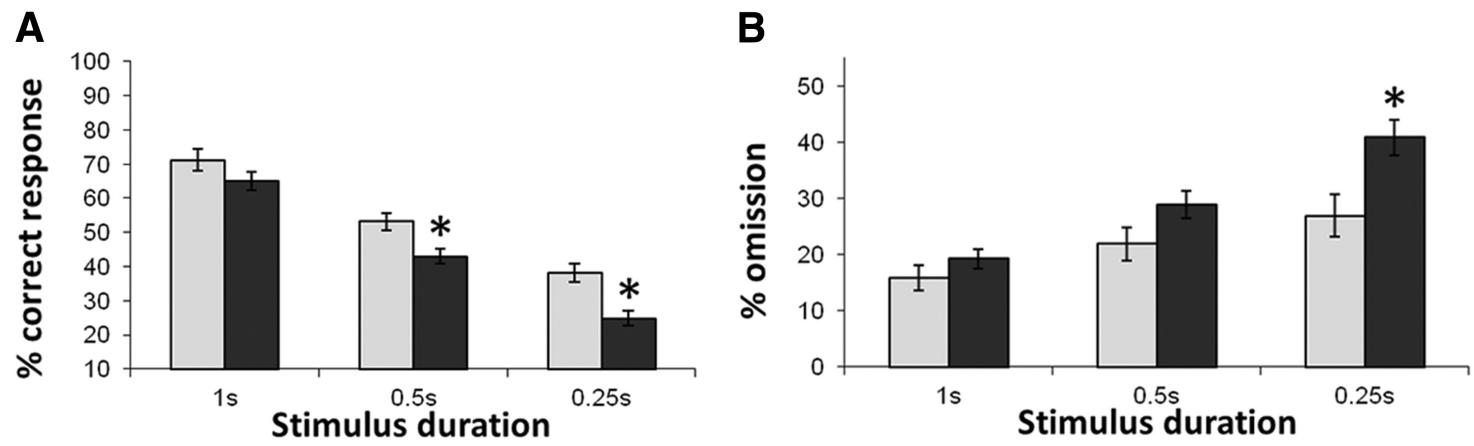

Figure 5. Rat performance on the visual version of the task. $A, B$, The figure shows the effect of decreased stimulus duration on the percentage of correct responses ( $\boldsymbol{A}$ ) and the percentage of omissions $(\boldsymbol{B})$ on the lights only version of the task for both surgical groups. Gray bars, Sham-lesioned rats; black bars, $\mathrm{ACh}-\mathrm{NBM}$-lesioned rats $\left(N_{\text {sham lesioned }}=10 ; N_{\mathrm{ACh}-\mathrm{NBM} \text { lesioned }}=15\right) .{ }^{*} p<0.05$. Error bars indicate SEM.

0.001; ACh-NBM-lesioned rats, $\left.F_{(1,14)}=154.29, p<0.001\right)$. On the $5 \mathrm{C}-\mathrm{o}$ version of the task, stimulus duration $\left(F_{(2,46)}=23.30\right.$, $p<0.001)$ and surgical group $\left(F_{(1,23)}=7.36, p=0.012\right)$ again significantly affected rats' performance. However, the two groups were differentially affected by the manipulation of stimulus duration $\left(F_{(2,46)}=8.92, p=0.001\right)$; namely, sham-lesioned rats maintained a high rate of correct responses when the stimulus duration was reduced from 1 to $0.5 \mathrm{~s}\left(F_{(1,9)}=1.99\right.$, n.s. $)$ and displayed a significant performance decrement only at an StimD of $0.25 \mathrm{~s}\left(F_{(1,9)}=7.94, p=0.020\right)$. On the other hand, the AChNBM-lesioned rats made fewer correct responses each time the stimulus duration was decreased (linear trend, $F_{(1,14)}=45.31$, $p<0.001)$.

Effect of the 192 IgG-saporin lesion of the NBM

Postsurgical testing at baseline conditions revealed no significant differences between the two surgical groups in the number of correct responses on either version of the task (5C-v, $F_{(1,23)}=2.25$, n.s.; 5C-o, $F_{(1,23)}=1.41$, n.s.). However, group differences began to emerge as we increased the attentional demands of the task. On the 5C-v task, ACh-NBM-lesioned rats made fewer correct responses than controls in sessions with StimDs of $0.5 \mathrm{~s}\left(F_{(1,23)}=9.41, p=0.005\right)$ and $0.25 \mathrm{~s}\left(F_{(1,23)}=14.98\right.$, $p=0.001$; Fig. $5 A$ ). The performance decrement of the ACh-NBMlesioned group came as a result of the increasing number of omitted trials in sessions with a shorter stimulus duration; namely, the AChNBM-lesioned rats had a higher percentage of omissions than the sham-lesioned rats at StimD $0.25 \mathrm{~s}\left(F_{(1,23)}=7.91, p=0.010\right.$; Fig. $5 B)$. It is interesting to note that the average number of correct responses at StimD 0.25 s on the $5 \mathrm{C}$-v task correlated significantly with the number of cholinergic NBM cells and with the average neocortical adjOD values [average adjOD $=\left(\operatorname{adjOD}_{\text {prelimbic }}\right.$ + ajdOD $\mathrm{drontal} \mathrm{area} 3+\operatorname{adjOD}_{\text {sensorimotor }}+\mathrm{ajdOD}_{\text {posterior parietal }}+$ ajdOD $_{\text {visual }} / 5$; Table 5]. On the other hand, the number of omissions at StimD $0.25 \mathrm{~s}$ was inversely correlated with the number of cholinergic NBM cells, as well as with the average neocortical adjOD values (Table 5). The number of correct responses and the number of omissions on the $5 \mathrm{C}-\mathrm{v}$ task at StimD $0.25 \mathrm{~s}$ did not significantly correlate (Pearson's $r$, at an $\alpha$ level of 0.05 ) with other histological measures. The stepwise Bonferroni method (Larzelere and Mulaik test; Larzelere and Mulaik, 1997) was 


$\begin{aligned} & \text { Table 5. Correlations between behavioral measures on visual and olfactory 5- } \\
& \text { CSRTTs and histological findings }\end{aligned}$
\begin{tabular}{lll}
\hline Behavioral measure & Number of ChAT-IR cells in the NBM & Average neocortical ajd0D \\
\hline $5 C-\mathrm{v}$ & & $r=0.48^{*}$ \\
$\%$ of correct responses & $r=0.65^{* *}$ & $r=-0.46^{*}$ \\
$\%$ of omissions & $r=-0.57^{*}$ & \\
$5 C-0$ & & $r=0.48^{*}$ \\
$\%$ of correct responses & $r=0.67^{* *}$ & $r=-0.49^{*}$ \\
$\%$ of omissions & $r=-0.73^{* * *}$ & $r=0.04$
\end{tabular}

The table shows Pearson's correlations coefficients calculated between the measures of behavioral performance on the visual and olfactory 5-CSRTTs and the histological measures. All correlations were significant at $\alpha=0.05$, following the stepwise Bonferroni correction for multiple correlations (Larzelere and Mulaik test).

${ }^{*} p<0.05 ;{ }^{* *} p<0.005 ;{ }^{* * *} p<0.001$.

implemented to correct for multiple correlations in this set of tests.

On the 5C-o task, the ACh-NBM-lesioned rats displayed a pattern of behavioral decrement similar to that observed in the 5C-v task; namely, the ACh-NBM-lesioned rats made fewer correct responses per session than controls under the conditions of high attentional demand (at StimD $0.5 \mathrm{~s}, F_{(1,23)}=4.46, p=0.046$; at StimD $0.25 \mathrm{~s}, F_{(1,23)}=23.95, p<0.001$; Fig. $6 A$ ). Again, a reduction in the number of correct responses was primarily driven by the increasing number of omissions per session (at StimD $0.5 \mathrm{~s}, F_{(1,23)}=6.07, p=0.022$; at StimD $0.25 \mathrm{~s}, F_{(1,23)}=$ $22.81, p<0.001$; Fig. $6 B$ ). The percentage of correct responses at StimD $0.25 \mathrm{~s}$ was correlated with the number of ChATimmunoreactive cells in the NBM and with the average neocortical adjOD (Table 5). Also, the percentage of omissions on the 5C-o task at StimD $0.25 \mathrm{~s}$ had significant negative correlation with the number of ChAT-immunoreactive cells in the NBM and with the average neocortical adjOD (Table 5). The numbers of correct responses and omissions did not significantly correlate (Pearson's $r$, at an $\alpha$ level of 0.05) with other histological measures. The stepwise Bonferroni method (Larzelere and Mulaik test) was implemented to correct for multiple correlations in this set of tests.

\section{Within-session variable ITI}

The attentional challenge with the within-session variable ITI did not significantly affect the rats' performance when compared to baseline (percentage of correct responses on $5 \mathrm{C}-\mathrm{v}, F_{(1,23)}=2.18$, n.s.; percentage of correct responses on $5 \mathrm{C}-\mathrm{o}, F_{(1,23)}=3.20$, n.s.). Furthermore, at this stage of testing, we did not observe significant difference between two surgical groups on any other measure of the 5-CSRTT performance (Tables 3, 4).

Correlations between the rats' performances on the two versions of the task

We calculated the Pearson's correlation coefficient between the rats' performance on the visual and odor versions of the 5-CSRTT, both in terms of the percentage of correct responses and the percentage of omissions per session. The stepwise Bonferroni method (Larzelere and Mulaik test) was implemented to correct for multiple correlations. The results are shown in Table 6. Under the baseline conditions and in the sessions with the variable ITI, we did not observe a systematic relationship between their behavior on the two tasks. However, as the attentional demands increased (StimDs 0.5 and $0.25 \mathrm{~s}$ ), the rats' performances on the $5 \mathrm{C}-\mathrm{v}$ and $5 \mathrm{C}$-o tasks were significantly correlated with each other.

\section{Discussion}

In the present study, we observed that the loss of cholinergic NBM cells and the resulting reduced cholinergic afferentation to the neocortex induced impairments in attentional processing for both the visual and odor stimuli. Although the two surgical groups performed comparably when tested under baseline conditions (StimD, $1 \mathrm{~s}$ ), under the conditions of high attentional demand the ACh-NBM-lesioned rats made fewer correct responses and made more omissions than controls. Importantly, we observed an equivalent pattern of behavioral impairment between the two versions of the task, and this behavioral decrement correlated with the reduced number of cholinergic NBM cells and with the reduced cholinergic availability in the neocortex. Since there was reduced ACh input to the visual cortex in ACh-NBM-lesioned rats, it is possible that their impaired performance on the $5 \mathrm{C}-\mathrm{v}$ was partially due to perceptual deficits. However, the ACh-NBM lesion did not affect the cholinergic input to olfactory sensory cortices. So the impaired performance of ACh-NBM-lesioned rats on the 5C-o was likely due to the reduced cholinergic modulation of the frontoparietal cortical attentional system. Collectively, these findings indicate that cortical cholinergic modulation may be involved in supramodal attentional processing of stimuli, i.e., regardless of their modality.

\section{Behavioral decrement following the cholinergic NBM lesion}

In the present study, bilateral injection of 192 IgG-saporin into rats' NBM caused a $52.13 \%$ reduction in the number of cholinergic NBM cells. Although the extent of the lesion was smaller than what have been reported in some previous studies (McGaughy et al., 2002; Harati et al., 2008), the lesion was accomplished with high neurochemical and neuroanatomical specificity; namely, immunohistochemistry revealed that the number of parvalbumin-immunoreactive cells in the NBM was unaffected by the lesion. In addition, the loss of cholinergic cells was restricted to the NBM, and the lesion did not affect the numbers of ChAT-immunoreactive cells in the MS/VDB or in the HDB. Consequently, the cholinergic afferentation to the hippocampus and olfactory cortex, respectively, remained intact. The extent of the reduction in cortical cholinergic availability was subtle, possibly because the cholinergic system of the ACh-NBM-lesioned animals was able to compensate to some extent and still provide the neocortex with some cholinergic input (De Rosa et al., 2001; McGaughy et al., 2002). Interestingly, the reduction in cholinergic markers in these ACh-NBM-lesioned rats is similar to that seen in humans diagnosed with mild cognitive impairment (Perry et al., 1977; Wilcock et al., 1982), and as such this lesion may be an appropriate model of age-associated mild cognitive impairment.

When tested under the conditions of high attentional demand, ACh-NBM-lesioned rats made fewer correct responses and more omissions than controls. Such a pattern of deficits on the 5-CSRTT reflects disrupted sustained attentional function as long as sensory-motor capacities, motivation, and executive function remain unaffected (Robbins, 2002). This exact pattern of behavior was observed in these ACh-NBMlesioned rats. Specifically, they performed comparably to controls under baseline conditions despite the observed reduction of ACh input to visual cortex (Lehmann et al., 2003); this indicates that they could perceive and respond to both the light and odor stimuli normally as long as the attentional demands of the task were low. Furthermore, reward latency, which is thought to reflect rats' motivational state, was not affected by the lesion. Finally, we did not observe abnormal impulsive or compulsive behavior, i.e., signs of disrupted executive function, in the ACh-NBM-lesioned rats, as indicated 

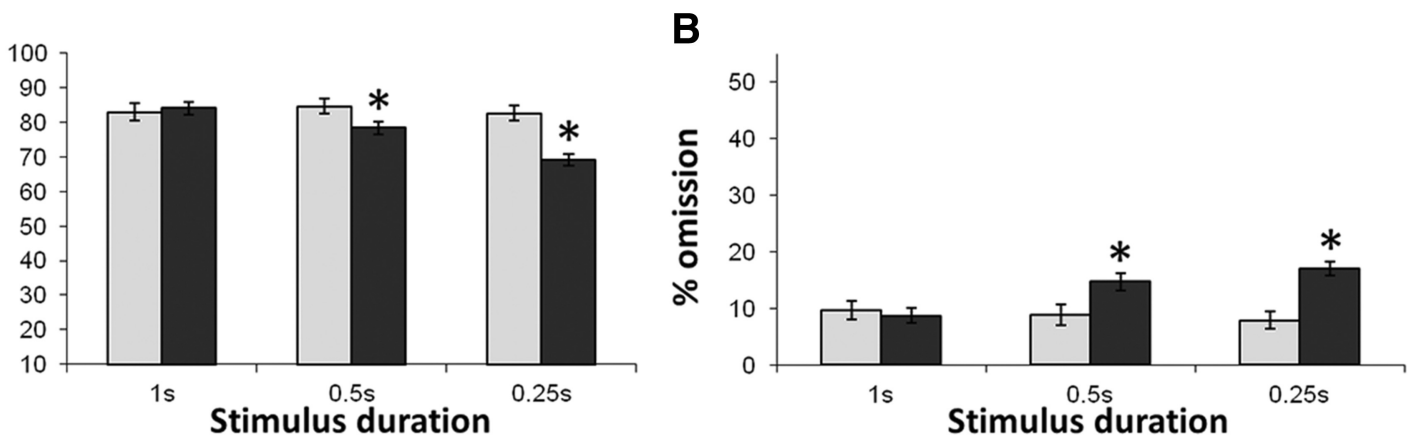

Figure 6. Rat performance on the olfactory version of the task. $A, B$, The figure shows the effect of decreased stimulus duration on the percentage of correct responses $(\boldsymbol{A})$ and percentage of omissions $(\boldsymbol{B})$ on the odor only version of the task for both surgical groups. Gray bars, Sham-lesioned rats; black bars, ACh-NBM-lesioned rats $\left(N_{\text {sham lesioned }}=10 ; N_{\text {ACh-NBM lesioned }}=15\right)$. ${ }^{*} p<0.05$. Error bars indicate SEM.

Table 6. Correlations between the rats' performances on two versions of the task

\begin{tabular}{lllll}
\hline \multirow{2}{*}{ Behavioral measure } & \multicolumn{4}{l}{ Testing condition } \\
\cline { 2 - 5 } & $1 \mathrm{~s}$ & $0.5 \mathrm{~s}$ & $0.25 \mathrm{~s}$ & Variable ITI \\
\hline \% correct responses & $r=0.31$ & $r=0.65^{*}$ & $r=0.53^{*}$ & $r=0.26$ \\
\% omission & $r=0.40$ & $r=0.79^{*}$ & $r=0.52^{*}$ & $r=0.27$ \\
\hline
\end{tabular}

Shown are the correlations (Pearson's $r$ value) between rat performances on the two versions of the task.

*Significant at $\alpha=0.05$, following the stepwise Bonferroni correction for multiple correlations (Larzelere and Mulaik test).

by the low numbers of premature and perseverative responses, respectively. This finding agrees with previous work that demonstrated that measures of executive function and response control on the 5-CSRTT are dependent on monoaminergic, rather than cholinergic, neurotransmission (Harrison et al., 1997; Higgins et al., 2003). Therefore, we can conclude that the behavioral decrement observed in the ACh-NBM-lesioned rats was likely caused by the impairments restricted to sustained attentional function.

The ACh-NBM-lesioned rats maintained a high percentage of correct responding in sessions with an StimD of $1 \mathrm{~s}$, regardless of temporal predictability of the target, and displayed attentional dysfunction only at a shorter StimD. Manipulations of StimD have been reported previously to cause similar changes in rat performance on the 5-CSRTT (Muir et al., 1995; McGaughy et al., 2002; Risbrough et al., 2002; Harati et al., 2008). It is thought that a short StimD impedes target detection, which, across prolonged testing period, increases task difficulty as well as the attentional effort associated with task performance (Robbins, 2002; Bari et al., 2008). It is also known that the higher difficulty of the attentional task correlates with an increase in frontoparietal cortical ACh activity (Himmelheber et al., 2001). Therefore, the lack of lesion effects at an StimD of $1 \mathrm{~s}$ was likely supported by the surviving cholinergic fibers providing sufficient ACh influx for normal performance at low task difficulty. However, when attentionally challenged, remaining cholinergic availability was not sufficient to respond to the increased attentional needs of the task.

\section{Cholinergic contribution to visual and olfactory attention}

The pattern of behavioral decrement that we observed in the ACh-NBM-lesioned rats was comparable between the 5C-o and $5 \mathrm{C}-\mathrm{v}$, and in both cases it indicated compromised sustained attentional function. A current model of sustained attention identifies the prefrontal and posterior parietal cortices as central nodes of the attentional cortical network and states that their activation and optimal functioning is dependent on cholinergic input from the NBM (Sarter et al., 2001; Hasselmo and McGaughy, 2004). According to this model, activation of the frontoparietal cortical network can modulate the input processing in primary sensory and sensory association cortices, either through direct connections or by recruiting cholinergic neurons from the $\mathrm{BF}$ and inducing $\mathrm{ACh}$ release into sensory areas. These influences are thought to focus processing resources of the sensory cortices toward relevant events in the environment, which, in turn, can facilitate target detection. This model has been validated in numerous studies that demonstrated that a cholinergic lesion of the NBM causes permanent behavioral deficits of sustained visual attention (Burk et al., 2002; Lehmann et al., 2003; Harati et al., 2008). Also, studies have revealed that sustained attention performance correlates with increased ACh overflow in the frontoparietal cortices (Passetti et al., 2000; Arnold et al., 2002; McGaughy et al., 2002), and with ACh-dependent changes in firing patterns of prefrontal cortical neurons (Gill et al., 2000). The present results are consistent with previous work, but we have shown for the first time that an ACh-NBM lesion also affects olfactory attention. This finding is not surprising given that functional neuroimaging studies in humans have reported activation of a classic frontoparietal cortical attentional network during sustained attentional processing of stimuli regardless of their modality (Pardo et al., 1991; Cohen et al., 1992; Fink et al., 1997). Also, paradigms that involve stimuli from multiple modalities have been used before with rodents to investigate the role of $\mathrm{ACh}$ in some attentional processes. It has been shown with such paradigms that ACh contributes to contextual set shifting (Allison and Shoaib, 2013), cross-modal feature binding (Botly and De Rosa, 2007, 2008, 2009), and attentional control (Newman and McGaughy, 2008). However, this study is the first to use a paradigm that specifically tests the detection of odor stimuli within the context of sustained attention.

We should note that the exact mechanism by which ACh contributes to olfactory attention remains unknown. Cholinergic innervation of the brain regions involved in the processing of odor stimuli, such as the olfactory bulb and the OC (McNamara et al., 2004), primarily originates in the HDB (Mesulam et al., 1983). $\mathrm{ACh}$ within the $\mathrm{OC}$ can induce changes in circuit dynamics resulting in enhanced processing of afferent inputs (Hasselmo and McGaughy, 2004; Devore and Linster, 2012). Given the reciprocal connections between the BF nuclei and the prefrontal cortex (Bigl et al., 1982), it is possible that this attentional network can recruit $\mathrm{HDB}$ cholinergic cells to induce ACh release that facilitates processing of odor stimuli. Furthermore, the NBM itself provides some ACh input to the OC (Lehmann et al., 1980; 
Grove, 1988), and the functional relevance of this input is yet to be described. In the present study, these projections were likely affected by the ACh-NBM lesion, which may have altered the functioning of the OC despite unchanged AChE OD within the OC in lesioned rats. In conclusion, since multiple channels of control may exist, further research is needed to fully describe the role of ACh in the modulation of olfactory attention. We argue that the relatively proficient performance on the $5 \mathrm{C}$-o is likely a reflection of the ease with which rats learn olfactory tasks. In future studies we will investigate additional methods of increasing the attentional challenge on the $5 \mathrm{C}$-o by, for instance, lowering the concentration of the odorant or introducing distractor stimuli.

In conclusion, the observed behavioral impairments in ACh-NBM-lesioned rats provide additional proof that sustained attentional function is dependent on cholinergic innervation of the neocortex, and that the decrement in attentional functioning correlates with the loss of cholinergic NBM neurons. Importantly, the nature of behavioral decrement remained identical on the 5C-v and 5C-o tasks. Collectively these data suggest the presence of a supramodal attentional modulatory cortical network whose activity is dependent on cholinergic innervation from the NBM.

\section{References}

Allison C, Shoaib M (2013) Nicotine improves performance in an attentional set shifting task in rats. Neuropharmacology 64:314-320. CrossRef Medline

Arnold HM, Burk JA, Hodgson EM, Sarter M, Bruno JP (2002) Differential cortical acetylcholine release in rats performing a sustained attention task versus behavioral control tasks that do not explicitly tax attention. Neuroscience 114:451-460. CrossRef Medline

Bari A, Dalley JW, Robbins TW (2008) The application of the 5-choice serial reaction time task for the assessment of visual attentional processes and impulse control in rats. Nat Protocols 3:759-767. CrossRef

Batchelor PE, Armstrong DM, Blaker SN, Gage FH (1989) Nerve growth factor receptor and choline acetyltransferase colocalization in neurons within the rat forebrain: response to fimbria-fornix transection. J Comp Neurol 2:187-204. Medline

Bentley P, Vuilleumier P, Thiel CM, Driver J, Dolan RJ (2003) Cholinergic enhancement modulates neural correlates of selective attention and emotional processing. Neuroimage 20:58-70. CrossRef Medline

Bigl V, Woolf NJ, Butcher LL (1982) Cholinergic projections from the basal forebrain to frontal, parietal, temporal, occipital, and cingulate cortices: a combined fluorescent tracer and acetylcholinesterase analysis. Brain Res Bull 8:727-749. CrossRef Medline

Botly LC, De Rosa E (2007) Cholinergic influences on feature binding. Behav Neurosci 121:264-276. CrossRef Medline

Botly LC, De Rosa E (2008) A cross-species investigation of acetylcholine, attention, and feature binding. Psychol Sci 19:1185-1193. CrossRef Medline

Botly LC, De Rosa E (2009) Cholinergic deafferentation of the neocortex using 192 IgG-saporin impairs feature binding in rats. J Neurosci 29: 4120-4130. CrossRef Medline

Botly LC, De Rosa E (2012) Impaired visual search in rats reveals cholinergic contributions to feature binding in visuospatial attention. Cereb Cortex 22:2441-2453. CrossRef Medline

Bucci DJ, Holland PC, Gallagher M (1998) Removal of cholinergic input to rat posterior parietal cortex disrupts incremental processing of conditioned stimuli. J Neurosci 18:8038-8046. Medline

Burk JA, Herzog CD, Porter MC, Sarter M (2002) Interactions between aging and cortical cholinergic deafferentation on attention. Neurobiol Aging 23:467-477. CrossRef Medline

Burk JA, Lowder MW, Altemose KE (2008) Attentional demands for demonstrating deficits following intrabasalis infusions of 192 IgG-saporin. Behav Brain Res 195:231-238. CrossRef Medline

Chiba AA, Bushnell PJ, Oshiro WM, Gallagher M (1999) Selective removal of cholinergic neurons in the basal forebrain alters cued target detection. Neuroreport 10:3119-3123. CrossRef Medline
Cohen RM, Semple WE, Gross M, King AC, Nordahl TE (1992) Metabolic brain pattern of sustained auditory discrimination. Exp Brain Res 92:165172. Medline

Corbetta M, Shulman GL (2002) Control of goal-directed and stimulusdriven attention in the brain. Nat Rev Neurosci 3:201-215. Medline

Dalley JW, McGaughy J, O'Connell MT, Cardinal RN, Levita L, Robbins TW (2001) Distinct changes in cortical acetylcholine and noradrenaline efflux during contingent and noncontingent performance of a visual attentional task. J Neurosci 21:4908-4914. Medline

Dalley JW, Theobald DE, Bouger P, Chudasama Y, Cardinal RN, Robbins TW (2004) Cortical cholinergic function and deficits in visual attentional performance in rats following $192 \mathrm{IgG}$-saporin-induced lesions of the medial prefrontal cortex. Cereb Cortex 14:922-932. CrossRef Medline

De Rosa E, Hasselmo ME, Baxter MG (2001) Contribution of the cholinergic basal forebrain to proactive interference from stored odor memories during associative learning in rats. Behav Neurosci 115:314-327. CrossRef Medline

Devore S, Linster C (2012) Noradrenergic and cholinergic modulation of olfactory bulb sensory processing. Front Behav Neurosci 6:52. Medline

Disney AA, Aoki C (2008) Muscarinic acetylcholine receptors in macaque V1 are most frequently expressed by parvalbumin-immunoreactive neurons. J Comp Neurol 507:1748-1762. CrossRef Medline

Fink GR, Halligan PW, Marshall JC, Frith CD, Frackowiak RS, Dolan RJ (1997) Neural mechanisms involved in the processing of global and local aspects of hierarchically organized visual stimuli. Brain 120:1779-1791. CrossRef Medline

Furey ML, Pietrini P, Haxby JV, Drevets WC (2008) Selective effects of cholinergic modulation on task performance during selective attention. Neuropsychopharmacology 33:913-923. CrossRef Medline

Gill TM, Sarter M, Givens B (2000) Sustained visual attention performanceassociated prefrontal neuronal activity: evidence for cholinergic modulation. J Neurosci 20:4745-4757. Medline

Greferath U, Trieu J, Barrett GL (2012) The p75 neurotrophin receptor has nonapoptotic antineurotrophic actions in the basal forebrain. J Neurosci Res 90:278-287. CrossRef Medline

Grove EA (1988) Efferent connections of the substantia innominata in the rat. J Comp Neurol 277:347-364. CrossRef Medline

Harati H, Barbelivien A, Cosquer B, Majchrzak M, Cassel JC (2008) Selective cholinergic lesions in the rat nucleus basalis magnocellularis with limited damage in the medial septum specifically alter attention performance in the five-choice serial reaction time task. Neuroscience 153:7283. CrossRef Medline

Harati H, Majchrzak M, Cosquer B, Galani R, Kelche C, Cassel JC, Barbelivien A (2011) Attention and memory in aged rats: Impact of lifelong environmental enrichment. Neurobiol Aging 32:718-736. CrossRef Medline

Harrison AA, Everitt BJ, Robbins TW (1997) Central 5-HT depletion enhances impulsive responding without affecting the accuracy of attentional performance: interactions with dopaminergic mechanisms. Psychopharmacology 133:329-342. CrossRef Medline

Hasselmo ME, McGaughy J (2004) High acetylcholine levels set circuit dynamics for attention and encoding and low acetylcholine levels set dynamics for consolidation. Prog Brain Res 145:207-231. CrossRef Medline

Herrero JL, Roberts MJ, Delicato LS, Gieselmann MA, Dayan P, Thiele A (2008) Acetylcholine contributes through muscarinic receptors to attentional modulation in V1. Nature 454:1110-1114. CrossRef Medline

Higgins GA, Enderlin M, Haman M, Fletcher PJ (2003) The 5-HT2A receptor antagonist M100,907 attenuates motor and 'impulsive-type' behaviours produced by NMDA receptor antagonism. Psychopharmacology 170:309-319. CrossRef Medline

Himmelheber AM, Sarter M, Bruno JP (2000) Increases in cortical acetylcholine release during sustained attention performance in rats. Brain Res Cogn Brain Res 9:313-325. CrossRef Medline

Himmelheber AM, Sarter M, Bruno JP (2001) The effects of manipulations of attentional demand on cortical acetylcholine release. Brain Res Cogn Brain Res 12:353-370. CrossRef Medline

Larzelere RE, Mulaik SA (1997) Single-sample tests for many correlations. Psychol Bull 84:557-569. CrossRef

Lehmann J, Nagy JI, Atmadia S, Fibiger HC (1980) The nucleus basalis magnocellularis: the origin of a cholinergic projection to the neocortex of the rat. Neuroscience 5:1161-1174. CrossRef Medline

Lehmann O, Grottick AJ, Cassel JC, Higgins GA (2003) A double dissociation between serial reaction time and radial maze performance in rats 
subjected to 192 IgG-saporin lesions of the nucleus basalis and/or the septal region. Eur J Neurosci 18:651-666. CrossRef Medline

Marques Pereira P, Cosquer B, Schimchowitsch S, Cassel JC (2005) HebbWilliams performance and scopolamine challenge in rats with partial immunotoxic hippocampal cholinergic deafferentation. Brain Res Bull 64:381-394. CrossRef Medline

McGaughy J, Dalley JW, Morrison CH, Everitt BJ, Robbins TW (2002) Selective behavioral and neurochemical effects of cholinergic lesions produced by intrabasalis infusions of 192 IgG-saporin on attentional performance in a five-choice serial reaction time task. J Neurosci 22:19051913. Medline

McNamara AM, Cleland TA, Linster C (2004) Characterization of the synaptic properties of olfactory bulb projections. Chem Senses 29:225-233. CrossRef Medline

Mesulam MM, Mufson EJ, Wainer BH, Levey AI (1983) Central cholinergic pathways in the rat: an overview based on an alternative nomenclature (Ch1-Ch6). Neuroscience 10:1185-1201. CrossRef Medline

Muir JL, Everitt BJ, Robbins TW (1994) AMPA-induced excitotoxic lesions of the basal forebrain: a significant role for the cortical cholinergic system in attentional function. J Neurosci 14:2313-2326. Medline

Muir JL, Everitt BJ, Robbins TW (1995) Reversal of visual attentional dysfunction following lesions of the cholinergic basal forebrain by physostigmine and nicotine but not by the 5-HT3 receptor antagonist, ondansetron. Psychopharmacology 118:82-92. CrossRef Medline

Newman LA, McGaughy J (2008) Cholinergic deafferentation of prefrontal cortex increases sensitivity to cross-modal distractors during a sustained attention task. J Neurosci 28:2642-2650. CrossRef Medline

Pardo JV, Fox PT, Raichle ME (1991) Localization of a human system for sustained attention by positron emission tomography. Nature 349:61-64. CrossRef Medline

Parikh V, Kozak R, Martinez V, Sarter M (2007) Prefrontal acetylcholine release controls cue detection on multiple timescales. Neuron 56:141154. CrossRef Medline

Passetti F, Dalley JW, O'Connell MT, Everitt BJ, Robbins TW (2000) Increased acetylcholine release in the rat medial prefrontal cortex during performance of a visual attentional task. Eur J Neurosci 12:3051-3058. CrossRef Medline
Paxinos G, Watson C (2007) The rat brain in stereotaxic coordinates, 6th edition. San Diego: Academic.

Perry EK, Gibson PH, Blessed G, Perry RH, Tomlinson BE (1977) Neurotransmitter enzyme abnormalities in senile dementia. Choline acetyltransferase and glutamic acid decarboxylase activities in necropsy brain tissue. J Neurol Sci 34:247-265. CrossRef Medline

Posner MI, Petersen SE (1990) The attention system of the human brain. Annu Rev Neurosci 13:25-42. CrossRef Medline

Risbrough V, Bontempi B, Menzaghi F (2002) Selective immunolesioning of the basal forebrain cholinergic neurons in rats: effect on attention using the 5-choice serial reaction time task. Psychopharmacology 164:71-81. CrossRef Medline

Robbins TW (2002) The 5-choice serial reaction time task: behavioural pharmacology and functional neurochemistry. Psychopharmacology 163:362380. CrossRef Medline

Sarter M, Givens B, Bruno JP (2001) The cognitive neuroscience of sustained attention: where top-down meets bottom-up. Brain Res Brain Res Rev 35:146-160. CrossRef Medline

Stewart C, Burke S, Marrocco R (2001) Cholinergic modulation of covert attention in the rat. Psychopharmacology 155:210-218. CrossRef Medline

Tait DS, Brown VJ (2008) Lesions of the basal forebrain impair reversal learning but not shifting of attentional set in rats. Behav Brain Res 187: 100-108. CrossRef Medline

Taniuchi M, Johnson EM Jr (1985) Characterization of the binding properties and retrograde axonal transport of a monoclonal antibody directed against the rat nerve growth factor receptor. J Cell Biol 101:1100-1106. CrossRef Medline

Voytko ML, Olton DS, Richardson RT, Gorman LK, Tobin JR, Price DL (1994) Basal forebrain lesions in monkeys disrupt attention but not learning and memory. J Neurosci 14:167-186. Medline

Wilcock GK, Esiri MM, Bowen DM, Smith CC (1982) Alzheimer's disease. Correlation of cortical choline acetyltransferase activity with the severity of dementia and histological abnormalities. J Neurol Sci 57:407-417. CrossRef Medline

Zaborszky L (2002) The modular organization of brain systems. Basal forebrain: the last frontier. Prog Brain Res 136:359-372. CrossRef Medline 